\title{
Impact of Insurance Status on the Prognosis of Acute Lower Limb Ischemia
}

\author{
Shyamal Premaratne1, J. David Neel², Cynthia X. Zhao³, Linda D. Doucet², Tze-Woei Tan², \\ Wayne W. Zhang2* \\ ${ }^{1}$ Hunter Holmes McGuire Veterans Administration Medical Center, Richmond, Virginia, USA \\ ${ }^{2}$ Department of Surgery, Louisiana State University Health Sciences Center, Shreveport, Louisiana, USA \\ ${ }^{3}$ Department of Pathology, Louisiana State University Health Sciences Center, Shreveport, Louisiana, USA \\ Email: *wzhan2@Isuhsc.edu
}

Received 17 March 2016; accepted 9 July 2016; published 12 July 2016

Copyright (C) 2016 by authors and Scientific Research Publishing Inc.

This work is licensed under the Creative Commons Attribution International License (CC BY).

http://creativecommons.org/licenses/by/4.0/

(c) (i) Open Access

\section{Abstract}

The objective of this study was to investigate if the insurance status of patients impacted the treatment options and prognosis in acute limb ischemia (ALI). A retrospective chart review was performed at a single university tertiary care center using ICD-9 codes for the diagnosis and procedure for ALI from January 2000 to January 2011. A total of 96 patients were diagnosed with ALI, comprising of 66 males and 30 females with a mean age of 56 years (range was 19 - 80 years). Time to presentation and prognosis (rate and level of amputation) were analyzed using insurance status as the independent variable. Patients covered under commercial insurance were compared to patients with Medicare and Medicaid and to patients without any insurance coverage. Statistical analysis was performed using the proportion $\mathrm{z}$ test to evaluate differences among the groups investigated. A " $p$ " value of $\leq \mathbf{0 . 0 5}$ was considered significant. In this study, ALI occurred more commonly in African Americans ( $p=0.0029)$ and in patients without insurance coverage regardless of race $(p=0.0034)$. Chronic obstructive pulmonary disease (COPD), hypertension (HTN), and acute renal failure (ARF) were significantly higher in the uninsured group, compared to the insured group ( $p=0.0005,0.0055$, and 0.0034 , respectively). The time to hospital admission was significantly longer in uninsured patients compared to the insured group $(p=0.0449)$. The rates of major amputation above the ankle were $46 \%$ in patients with commercial insurance, $62 \%$ in the government insurance (Medicare and Medicaid) group, and 51\% in the uninsured group. There was no significant difference in major versus minor amputation in patients with commercial insurances. However, the rates of major amputation were significantly higher than the rates of minor amputation in both Medicare and Medicaid and uninsured patients $(p=0.005$, and $<0.0001$, respectively). With respect to acute lower limb ischemia, African Americans presented more frequently and were more likely to be uninsured. The incidences of COPD, HTN, and ARF were significantly higher in uninsured patients. The majority of the amputations in Medicare and Medicaid

\footnotetext{
${ }^{*}$ Corresponding author.
}

How to cite this paper: Premaratne, S., Neel, J.D., Zhao, C.X., Doucet, L.D., Tan, T.-W. and Zhang, W.W. (2016) Impact of Insurance Status on the Prognosis of Acute Lower Limb Ischemia. World Journal of Cardiovascular Diseases, 6, $218-223$. 
and uninsured populations were likely above the ankle. Results suggest that government insurance coverage does not prevent major amputation in patients with ALI.

\title{
Keywords
}

\author{
Ischemia, Lower Extremity, Amputation, Insurance
}

\section{Introduction}

In the current climate of health care reform in general and the Affordable Healthcare Act in particular, it is appropriate to look at insurance status on the prognosis of vascular disease [1]-[4]. Acute limb ischemia (ALI) is a serious condition where there is a sudden decrease in limb perfusion causing a potential threat to limb viability manifested by ischemic rest pain, ischemic ulcers, and/or gangrene [5]. Patients who present more than two weeks after the onset of the acute event are considered to have chronic limb ischemia. Management of acute arterial occlusion has remained as a challenge for vascular specialists. Surgical thromboembolectomy and bypass grafting has been the mainstay of therapy for many years [6]. Subsequently, thrombolytic therapy and percutaneous transluminal angioplasty (PTA) became treatment options for selected patients [7] [8]. Despite these advances, morbidity and mortality, and the rates of limb loss from ALI remain high [9]. Regardless of the treatment modality used, early diagnosis and rapid initiation of therapy are essential in order to salvage the ischemic extremity.

Acute arterial occlusion leading to ischemia can be the result of an embolus from a distant source lodging into a more distal vessel, acute thrombosis of a previously patent artery, or a stent/graft, and dissection of or direct trauma to an artery. While the majority of arterial emboli that travel to the extremities originate in the heart, the lower extremities are more vulnerable compared to the upper [10]. Potential sources of emboli from the heart include atrial thrombus formation due to atrial fibrillation, left ventricular thrombus formation following myocardial infarction or a dysfunctional left ventricle, and debris from prosthetic valves and infected cardiac valves. Arterial embolization of thrombus or plaque originating from aneurysms or atherosclerotic lesions is another well-documented occurrence accounting for $20 \%$ of peripheral emboli. These typically lodge where there is an acute narrowing of the artery, such as an atherosclerotic plaque or a point where the vessel branches such as the common femoral, common iliac, and popliteal artery bifurcations.

In comparison with thromboemboli, atheroemboli are less likely to produce symptoms of ALI. Although more commonly associated with cryptogenic stroke, paradoxical emboli can also cause acute limb ischemia affecting the upper or lower extremity [11]-[16]. One series found that 2\% - 4\% of embolic events over an eight-year period were due to paradoxical emboli. However, the source remained unknown in $20 \%$ of patients [17]. The age of patients with paradoxical emboli was younger than the average for the entire series (39 versus 68 years). Patients presented with acute ischemia of an extremity, symptoms of deep vein thrombosis, or pulmonary embolism. None of the patients had evidence of cardiac or peripheral artery disease. Arterial injury due to trauma to the extremities (blunt or penetrating) can also lead to acute limb ischemia. In the present study, we looked at the prognosis of ALI from a financial point of view more than from its pathophysiology, looking at racial and ethnic disparities and prognosis [18]. We reviewed the charts of patients with ALI with an emphasis on their insurance status.

\section{Patients and Methods}

The Institutional Review Board (IRB) of the participating university tertiary care center approved this retrospective study. It was necessary to obtain patient consent as this was a retrospective review of medical records from the Louisiana State University Health Sciences Center, Shreveport, Louisiana using ICD-9 codes for the diagnosis and procedure for ALI from January 2000 to January 2011. A total of 96 patients were diagnosed with ALI, which comprised of 66 males and 30 females with a mean age of 56 years (range was 19 - 80 years). Time to presentation and prognosis (rate and level of amputation) were analyzed using insurance status as the independent variable. Patients covered under commercial insurance were compared to patients with government health insurance (Medicare and Medicaid) and to patients without any insurance coverage. Statistical analysis was per- 
formed using the proportion $\mathrm{z}$ test to evaluate differences among the groups investigated. A "p" value of $\leq 0.05$ was considered significant.

\section{Results}

Data collected in this retrospective study appear in Table 1. Acute Limb Ischemia (ALI) occurred more commonly in African Americans $(\mathrm{p}=0.0029)$ and in patients without insurance coverage regardless of race $(\mathrm{p}=$ 0.0034). It was seen that chronic obstructive pulmonary disease (COPD), hypertension (HTN), and acute renal failure (ARF) were also significantly higher in the uninsured group compared to the insured $(p=0.0005,0.0055$, and 0.0034 , respectively). The time to hospital admission was significantly longer in uninsured patients compared to the insured group $(\mathrm{p}=0.0449)$. Major amputation rates above the ankle were $46 \%$ in patients with commercial insurance, $62 \%$ in the government insurance (Medicare and Medicaid) group, and $51 \%$ in the uninsured group. There was no significant difference in major versus minor amputation in patients with commercial insurances. However, the rates of major amputation were significantly higher than the rates of minor amputation in both Medicare and Medicaid and uninsured patients ( $\mathrm{p}=0.005$, and $<0.0001$, respectively). Table 1 shows the data gathered in this study as well as the statistical analysis.

\section{Discussion}

\subsection{Incidence of Arterial Disease}

On average, the incidence of acute peripheral arterial occlusion is approximately 1.5 cases per 10,000 persons

Table 1. Two-proportion Z-test is used. One-proportion Z-test is only used for black vs white comparison within each group.

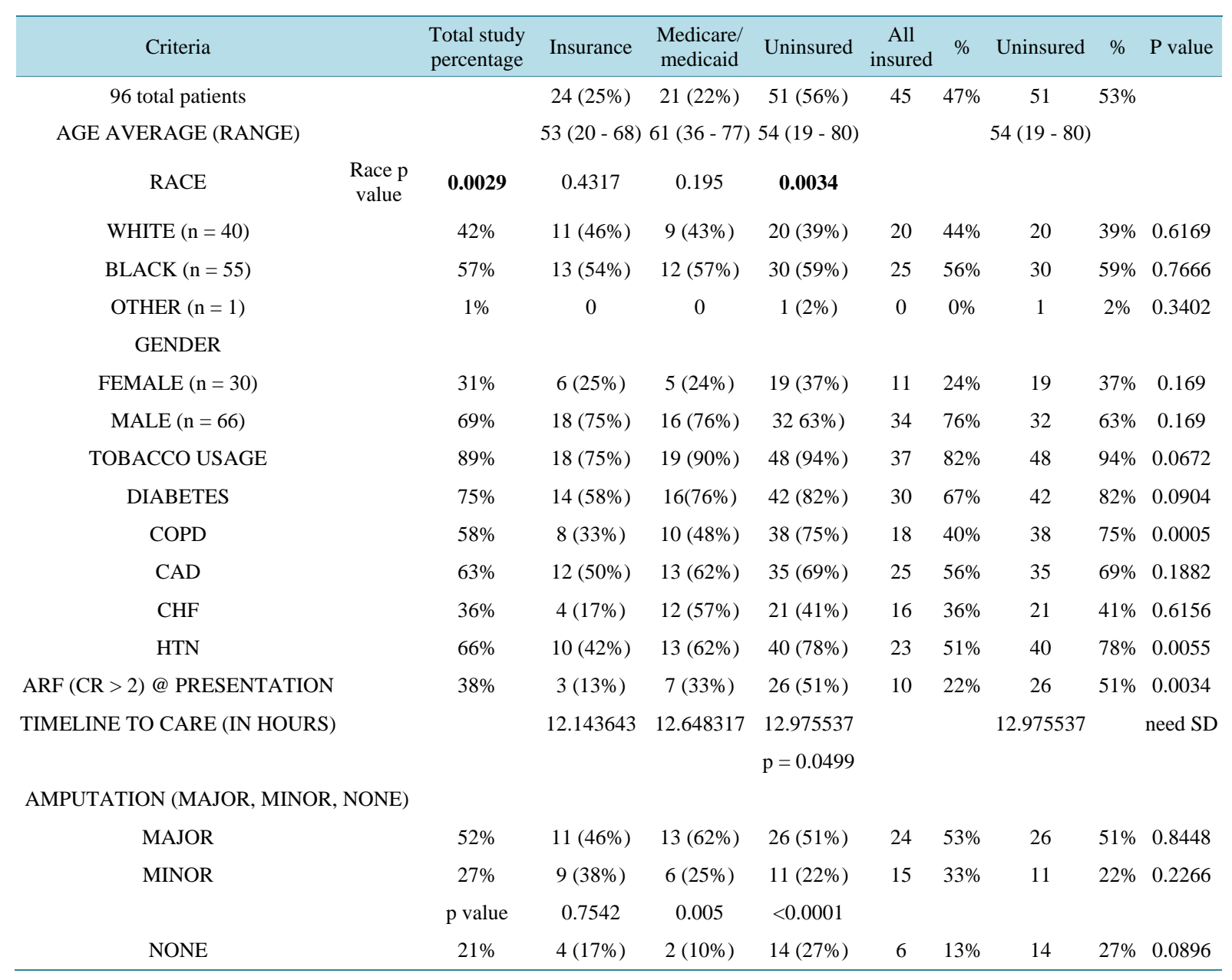


per year [19]. However, during the past fifteen years, this number has been decreasing on an annual basis. That said, major amputation (MA) continues to be a primary therapy in these cases and is frequently the only treatment offered for ALI. A "pathway to amputation" has characterized the treatment of limb ischemia in the United States where amputation was the first procedure in $67 \%$ of Medicare patients. A study done in 2012 involving 20,464 patients on Medicare with critical limb ischemia who underwent major amputation reported very similar results [20]. Today, approximately 65,000 - 70,000 MAs are performed for peripheral arterial disease (PAD) on an annual basis and the vast majority of them will suffer from critical limb ischemia (CLI). 25\% - 33\% of Medicare patients will undergo primary amputation [21] [22].

Many studies have clearly shown that the probability of a patient undergoing amputation will depend largely on who you are and where you live [21] [23] [24]. Minorities, lower social-economic status, age, sex, insurance status, and low hospital volume have been shown to greatly influence the probability of a major amputation. Patients on Medicare and Medicaid are more likely to undergo major amputation compared with patients on private insurance plans. Geographic location is also associated with variations in vascular procedures offered to Medicare patients before ultimately undergoing a MA. Similar amputation rates are found in neighboring hospital referral regions. Geographic differences in amputation numbers exist even after adjusting for age sex, race and other causes of morbidity. Compared with other surgical procedures, major amputation has a high rate of peri-operative morbidity and mortality. Amputations, both above and below the knee are among the top five surgical procedures with the highest mortality peri-operatively [25]. 5\% - 10\% of below knee and $15 \%-20 \%$ of above knee amputees die prior to discharge. By contrast, rates of peri-operative mortality for infra-inguinal bypass and end vascular revascularization are $2 \%-8 \%$ and $1 \%-3 \%$ respectively [26]-[28].

\subsection{Cost of Amputation}

Since amputation is an eventuality in lower limb ischemia, we must consider its cost. Major amputation is the $6^{\text {th }}$ most expensive surgical procedure in the United States [29]. The total cost of amputations is estimated at 10.6 billion dollars annually. Medicare and Medicaid paid out $80 \%$ of this bill. This is clearly a major drain on federal resources. This amount is broadly divided in to $45 \%$ for hospital costs, $20 \%$ for follow up, $12 \%-16 \%$ for nursing home care and the remainder for rehabilitation and for medical equipment. This data begs the question: Is the paying for amputations the best allocation of scare health resources? Since $80 \%$ of the cost is borne by the federal government, it is prudent to look at alternative treatments to limb ischemia such as bypass surgery and endovascular revascularization. A study done by Barshes and colleagues [30] compared primary amputation versus revascularization. This is the only study of its kind in the last 15 years. A similar study done in 1999 also concluded that amputation was less cost effective than bypass surgery.

\subsection{Distribution of Acute Lower Limb Ischemia}

Limb ischemia and amputation are closely related to insurance costs, which in turn are tied to Medicare and Medicaid. Amputees use hospital resources extensively with frequent re-admissions, especially in the first month. 30-day readmissions for Medicare patients who undergo amputation for limb ischemia exceed those of the average Medicare patient (26\% versus 20\%) [31]. Amputees require frequent hospitalization easily surpassing patients with other chronic diseases [32] [33]. To put this in perspective, amputees were re-admitted 19.5 times per person-year with a hospital stay of 71.2 days per person-year [33]. The cost of amputation in limb ischemia is close to 11 billion dollars not counting societal costs and that due to lost productivity.

It is clear that ALI is seen significantly more often in African Americans compared to Caucasians ( $\mathrm{p}=$ 0.0029). In the uninsured group, African American patients out number Caucasian patients $(\mathrm{p}=0.0034)$. COPD, HTN, and ARF are all significantly higher as well in uninsured patients $(\mathrm{p}=0.0005,0.0055$, and 0.0034 respectively). It is difficult to compare published results of the treatment of acute extremity ischemia because of the different methods used to describe the severity of ischemia and differences in the duration of ischemia. However, it is clear that, in spite of optimal therapy, acute extremity ischemia is associated with high rates of hospital morbidity and mortality, and high rates of limb loss. Limb loss rates as high as $30 \%$ and hospital mortality as high as $20 \%$ have been quoted in surgical series [6].

\section{Conclusion}

A majority of amputations are above the knee. Cardiopulmonary complications account for the majority of the 
deaths, underscoring the severity of the baseline medical condition of these patients. Approximately $15 \%-20 \%$ of patients die within one year after presentation, usually from the medical illnesses that predisposed them to acute limb ischemia [34]. Studies have clearly shown a correlation with advancing presentation, and advancing age in femoro-popliteal vascularization [35]. Not only were African American numbers higher in this category, but they were more likely to be uninsured as well [36].

\section{References}

[1] Giacovelli, J.K., Eqorova, N., Nowygrod, R., Gellins, A., Kent, K.C. and Morrissey, N.J. (2008) Insurance Status Predicts Access to Care and Outcomes of Vascular Disease. Journal of Vascular Surgery, 48, 905-911. http://dx.doi.org/10.1016/j.jvs.2008.05.010

[2] Reinecke, H., Unrath, M., Freisinger, E., Bunzemeier, H., Meyborg, M., Luders, F., Gebauer, K., Roeder, N., Berger, K. and Malyar, N.M. (2015) Peropheral Arterial Disease and Critical Limb Ischemia: Still Poor Outcomes and Lack of Guideline Adherence. European Heart Journal, 36, 932-938. http://dx.doi.org/10.1093/eurheartj/ehv006

[3] Tsai, F.C., Lan, Y.C., Muo, C.H., Yang, Y.F., Sung, F.C., Chen, R.Y., Lyu, S.Y. and Morisky, D.E. (2015) Subsequent Ischemic Events Associated with Lower Extremity Amputations in Patients with Type 2 Diabetes: A Population Based Cohort Study. Diabetes Research and Clinical Practice, 107, 85-93. http://dx.doi.org/10.1016/j.diabres.2014.09.017

[4] Baril, D.T., Ghosh, K. and Rosen, A.B. (2014) Trends in the Incidence, Treatment, and Outcomes of Acute Lower Extremity Ischemia in the United States Medicare Population. Journal of Vascular Surgery, 60, 669-677. http://dx.doi.org/10.1016/j.jvs.2014.03.244

[5] Norgren, L., Hiatt, W.R., Dormandy, J.A., Nehler, M.R., Harris, K.A. and Fowkes, F.G. (2007) TASC II Working Group. Inter-Society Consensus for the Management of Peripheral Arterial Disease (TASC II). Journal of Vascular Surgery, 45, S5-67. http://dx.doi.org/10.1016/j.jvs.2006.12.037

[6] Yeager, R.A., Moneta, G.L., Taylor Jr, L.M., Hamre, D.W., McÇonnell, D.B. and Porter, J.M. (1992) Surgical Management of Severe Acute Lower Extremity Ischemia. Journal of Vascular Surgery, 15, 385-393. http://dx.doi.org/10.1016/0741-5214(92)90260-F

[7] Kashyap, V.S., Gilani, R., Bena, J.F., Bannazadch, M. and Sarac, T.P. (2011) Endovascular Therapy for Acute Limb Ischemia. Journal of Vascular Surgery, 53, 340-346. http://dx.doi.org/10.1016/j.jvs.2010.08.064

[8] Hynes, B.G., Margey, R.J., Ruggiero $2^{\text {nd }}$, N., Kieman, T.J., Rosenfield, K. and Jaff, M.R. (2012) Endovascular Management of Acute Limb Ischemia. Annals of Vascular Surgery, 26, 110-124. http://dx.doi.org/10.1016/j.avsg.2011.05.017

[9] Baril, D.T., Patel, V.I., Judelson, D.R., Goodney, P.P., McPhee, J.T. and Hevelone, N.D. (2013) Outcomes of Lower Extremity Bypass Performed for Acute Limb Ischemia. Journal of Vascular Surgery, 58, 949-956. http://dx.doi.org/10.1016/j.jvs.2013.04.036

[10] Clagett, G.P., Sobel, M., Jackson, M.R., Lip, G.Y., Tangelder, M. and Verhaeghe, R. (2004) Antithrombotic Therapy in Peripheral Arterial Occlusive Disease: The Seventh ACCP Conference on Antithrombotic and Thrombolytic Therapy. Chest, 126, 609S-626S. http://dx.doi.org/10.1378/chest.126.3_suppl.609S

[11] Miller, S., Causey, M.W., Schachter, D., Anderson, C.A. and Singh, N. (2010) A Case of Limb Ischemia Secondary to Paradoxical Embolism. Vascular and Endovascular Surgery, 44, 604-608. http://dx.doi.org/10.1177/1538574410374656

[12] Dao, C.N. and Tobis, J.M. (2011) PFO and Paradoxical Embolism Producing Events Other than Stroke. Catheterization and Cardiovascular Interventions, 77, 903-909. http://dx.doi.org/10.1002/ccd.22884

[13] Hugl, B., Klein-Weigel, P., Posch, L., Greiner, A. and Fraedrich, G. (2005) Peripheral Ischemia Caused by Paradoxical Embolization: An Underestimated Problem? Mount Sinai Journal of Medicine, 72, 200-206.

[14] Travis, J.A., Fuller, S.B., Ligush Jr., J., Plonk Jr., G.W., Geary, R.L. and Hansen, K.J. (2001) Diagnosis and Treatment of Paradoxical Embolus. Journal of Vascular Surgery, 34, 860-865. http://dx.doi.org/10.1067/mva.2001.118815

[15] Herity, N.A. and Dalzell, G.W. (1997) Venous Thrombosis Causing Arterial Embolization to the Same Limb through a Patent Foramen Ovale. Clinical Cardiology, 20, 893-896. http://dx.doi.org/10.1002/clc.4960201020

[16] Paes, E.H., Greven, T. and Heredia, D. (1997) Paradoxical Embolism and Aortic occlusion: A Case Report. International Angiology, 16, 72-75.

[17] AbuRahma, A.F. and Downham, L. (1996) The Role of Paradoxical Arterial Emboli of the Extremities. The American Journal of Surgery, 172, 214-217. http://dx.doi.org/10.1016/S0002-9610(96)00155-9

[18] Karve, S.J., Balkrishnan, R., Mohammad, Y.M. and Levine, D.A. (2011) Racial/Ethnic Disparities in Emergency Department Waiting Time for Stroke Patients in the United States. Journal of Stroke and Cerebrovascular Diseases, 20, 30-40. http://dx.doi.org/10.1016/j.jstrokecerebrovasdis.2009.10.006 
[19] Nasser, T.K., Mohler, E.R., Wilensky, R.L. and Hathaway, D.R. (1995) Peripheral Vascular Complications Following Coronary Interventional Procedures. Clinical Cardiology, 18, 609-614. http://dx.doi.org/10.1002/clc.4960181105

[20] Goodney, P.P., Travis, L.L., Nallamothu, B.K., Holman, K., Suckow, B., Henke, P.K., Lucas, F.L., Goodman, D.C., Birkmeyer, J.D. and Fisher, E.S. (2012) Variation in the Use of Lower Extremity Vascular Procedures for Critical Limb Ischemia. Circulation: Cardiovascular Quality and Outcomes, 5, 94-102. http://dx.doi.org/10.1161/circoutcomes.111.962233

[21] Henry, A.J., Hevelone, N.D., Belkin, M.B. and Nguyen, L.L. (2011) Socioeconomic and Hospital Related Predictors of Amputation for Critical Limb Ischemia. Journal of Vascular Surgery, 53, 330-339. http://dx.doi.org/10.1016/j.jvs.2010.08.077

[22] Baser, O., Verpillat, P., Gabriel, S. and Wang, L. (2013) Prevalence, Incidence and Outcomes of Critical Limb Ischemia in the US Medicare Population. Vascular Disease Management, 10, E26-E36.

[23] Holman, K.H., Henke, P.K., Dimick, J.B. and Birkmeyer, J.D. (2011) Racial Disparities in the Use of Revascularization before Leg Amputation in Medicare Patients. Journal of Vascular Surgery, 54, 420-426. http://dx.doi.org/10.1016/j.jvs.2011.02.035

[24] Guadagnoli, E., Ayanian, J.Z., Gibbons, G., McNeil, B.J., LoGerfo, F.W., Guadagnoli, E., Ayanian, J.Z., Gibbons, G., McNeil, B.J. and LoGerfo, F.W. (1995) The influence of Race on the Use of Surgical Procedures for Treatment of Peripheral Vascular Disease of the Lower Extremities. Archives of Surgery, 130, 381-386. http://dx.doi.org/10.1001/archsurg.1995.01430040043006

[25] Ghaferi, A.A., Birkmeyer, J.D. and Dimick, J.B. (2009) Variation in Hospital Mortality with Inpatient Surgery. The New England Journal of Medicine, 361, 1368-1375. http://dx.doi.org/10.1056/NEJMsa0903048

[26] Khuri, S.F., Henderson, W.G., DePalma, R.G., Mosca, C., Healey, N.A. and Kumbhani, D.J. (2005) Determinants of Long-Term Survival after Major Surgery and the Adverse Effect of Postoperative Complications. Annals of Surgery, 242, 326-341, Discussion 341-343. http://dx.doi.org/10.1097/01.sla.0000179621.33268.83

[27] Vogel, T.R., Dombrovskiy, V.Y., Haser, P.B. and Graham, A.M. (2011) Evaluating Preventable Adverse Safety Events after Elective Lower Extremity Procedures. Journal of Vascular Surgery, 54, 706-713. http://dx.doi.org/10.1016/j.jvs.2011.03.230

[28] Sachs, T., Pomposelli, F., Hamdan, A., Wyers, M. and Schermerhorn, M. (2011) Trends in the National Outcomes and Costs for Claudication and Limb Threatening Ischemia: Angioplasty vs Bypass Graft. Journal of Vascular Surgery, 54, 1021-1031. http://dx.doi.org/10.1016/j.jvs.2011.03.281

[29] Elixhauser, A. and Andrews, R.M. (2010) Profile of Inpatient Operating Room Procedures in US Hospitals in 2007. Archives of Surgery, 145, 1201-1208. http://dx.doi.org/10.1001/archsurg.2010.269

[30] Barshes, N.R., Chambers, J.D., Cohen, J. and Belkin, M. (2012) Cost-Effectiveness in the Contemporary Management of Critical Limb Ischemia with Tissue Loss. Journal of Vascular Surgery, 56, 1015-1024. http://dx.doi.org/10.1016/j.jvs.2012.02.069

[31] Jencks, S.F., Williams, M.V. and Coleman, E.A. (2009) Rehospitalizations among Patients in the Medicare Fee-forService Program. The New England Journal of Medicine, 360, 1418-1428. http://dx.doi.org/10.1056/NEJMsa0803563

[32] Dillingham, T.R., Pezzin, L.E. and Shore, A.D. (2005) Reamputation, Mortality, and Health Care Costs among Persons with Dysvascular Lower-Limb Amputations. Archives of Physical Medicine and Rehabilitation, 86, 480-486. http://dx.doi.org/10.1016/j.apmr.2004.06.072

[33] Henry, A.J., Hevelone, N.D., Hawkins, A.T., Watkins, M.T., Belkin, M. and Nguyen, L.L. (2013) Factors Predicting Resource Utilization and Survival after Major Amputation. Journal of Vascular Surgery, 57, 784-790. http://dx.doi.org/10.1016/j.jvs.2012.09.035

[34] Karmody, A.M., Powers, S.R., Monaco, V.J. and Leather, R.P. (1976) "Blue Toe” Syndrome. An Indication for Limb Salvage Surgery. Archives of Surgery, 111, 1263-1268. http://dx.doi.org/10.1001/archsurg.1976.01360290097015

[35] Durham, C.A., Mohr, M.C., Parker, F.M., Bogey, W.M., Powell, C.S. and Stoner, C.M. (2010) The Impact of Socioeconomic Factors on Outcomes and Hospital, Costs Associated with Femoropopliteal Revascularization. Journal of Vascular Surgery, 52, 606-607. http://dx.doi.org/10.1016/j.jvs.2010.04.011

[36] Cromwell, J., McCall, N.T., Burton, J. and Urato, C. (2005) Race/Ethnic Disparities in Utilization of Lifesaving Technologies by Medicare Ischemic Heart Disease Beneficiaries. Medical Care, 43, 330-337. http://dx.doi.org/10.1097/01.mlr.0000156864.80880.aa 


\section{Submit or recommend next manuscript to SCIRP and we will provide best service for you:}

Accepting pre-submission inquiries through Email, Facebook, Linkedin, Twitter, etc A wide selection of journals (inclusive of 9 subjects, more than 200 journals)

Providing a 24-hour high-quality service

User-friendly online submission system

Fair and swift peer-review system

Efficient typesetting and proofreading procedure

Display of the result of downloads and visits, as well as the number of cited articles

Maximum dissemination of your research work

Submit your manuscript at: http://papersubmission.scirp.org/ 